\title{
Thyroid-Binding Globulin Deficiency
}

National Cancer Institute

\section{Source}

National Cancer Institute. Thyroid-Binding Globulin Deficiency. NCI Thesaurus. Code C131022.

Subnormal concentration of thyroid-binding globulin. 